\title{
Functional properties of the three hemoglobin phenotypes of Nelore cattle
}

\author{
A. Di Vito, A.R. Schwantes and M.L.B. Schwantes \\ Department of Genetics and Evolution, Universidade Federal de São Carlos, São Carlos, SP, Brazil.
}

\begin{abstract}
Blood and stripped hemoglobin from Nelore cattle individuals were submitted to oxygen equilibrium experiments in both gasometric and spectrophotometric methods. No difference was detected in oxygen affinity and Bohr effect among $\mathrm{Hb} \mathrm{A}, \mathrm{Hb}$ B and $\mathrm{Hb} \mathrm{AB}$ in experiments with both blood and stripped hemoglobin, in the presence and absence of the chloride ion. However, $n$ values (Hill plots) were higher in $\mathrm{Hb} \mathrm{B}$ and $\mathrm{Hb} \mathrm{AB}(>2)$ than in $\mathrm{Hb} \mathrm{A}(<2)$.
\end{abstract}

Key words: Allohemoglobins, functional properties, Nelore cattle, cooperativity, Bohr effect, modulatators effect. Received: July 3, 1998; accepted: August 17, 2000.

\section{Introduction}

Hemoglobin polymorphism in mixed European/Indian (Bos taurus taurus/B. t. indicus) Algerian cattle was first described by Cabannes \& Serrain (1). This polymorphism is due to a $\beta$ chain variant - $\beta B$ (2) which shows a Mendelian mode of inheritance, presenting 3 phenotypes $\mathrm{Hb} \mathrm{A}, \mathrm{Hb} \mathrm{B}$ and $\mathrm{Hb} \mathrm{AB}$. Thereafter, several papers $(3,4,5)$ describing allele frequencies have been published. The gene for this $\beta \mathrm{B}$ chain is found mainly in tropical herds, pure Indian or mixed with European cattle. Ayala (6) claimed that this polymorphism would be maintained by natural selection. However, no direct evidence of differences in fitness among the three phenotypes has been found. On the other hand, no description of functional properties of $\mathrm{Hb} \mathrm{B}$ or $\mathrm{Hb} \mathrm{AB}$ has been found in the literature available.

Bunn (7) demonstrated that ruminant (including $\mathrm{Hb} \mathrm{A}$ from a Holstein cow) and cat hemoglobins show intrinsically low oxygen affinity and are weakly reactive to 2,3-diphosphoglycerate (2,3-DPG), the main hemoglobin function modulator of mammals. However, Weber and coworkers (8), comparing yak hemoglobins with cow $\mathrm{Hb} \mathrm{A}$, showed a not so weak 2,3-DPG effect in the latter.

Fronticelli (9) claimed that $\mathrm{Cl}^{-}$ions would be responsible for the $\mathrm{Hb}$ function modulation in bovine cattle, as DPG is for human hemoglobin. However, Perutz and Fermi (10) did not confirm these results.

In order to find out if there are some differences in the functional properties of the three hemoglobin phenotypes, oxygen equilibrium experiments, including the effect of 2,3-DPG and $\mathrm{Cl}^{-}$, were carried out, using Nelore cattle.

Send correspondence to A. Di Vito. Caixa Postal 676, 13565-905 São Carlos, SP, Brazil. E-mail: dars@ power.ufscar.br.

\section{Material and Methods}

The Nelore cattle used here belong to the Fazenda Canchim, a unit of EMBRAPA (Empresa Brasileira de Agro-Pecuária), located in São Carlos, SP, Brazil.

Blood was obtained from the jugular vein with heparinised syringes. Red blood cells were separated from plasma by centrifugation. After washing the cells three times with isotonic saline, water was added to the packed red cells in a 2:1 ratio. The hemolysates were produced by freezing and thawing three times and were then centrifuged for $15 \mathrm{~min}$, at $12,100 \mathrm{~g}$, at $4{ }^{\circ} \mathrm{C}$.

Stripped hemoglobin was obtained by passing the hemolysate through a Sephadex G-25 column using Tris $\mathrm{HCl} 0.5 \mathrm{M}$ buffer and $\mathrm{Cl}^{-}$-free hemolysate with Hepes-Tris $0.5 \mathrm{M}$ buffer $(11,12)$.

Electrophoreses were carried out using hydrolyzed maize starch and Tris Borate-EDTA buffers (13) to check the hemoglobin phenotypes.

Whole blood oxygen equilibrium experiments were carried out using the gasometric method (14). The spectrophotometric method was used for the hemolysates (15).

Intraerythrocytic phosphate extracts were prepared (16). The phosphates were separated in a Q Sepharose column $(11 \mathrm{~cm} \times 1 \mathrm{~cm})$ controlled by a FPLC (Fast Protein Liquid Chromatography) system. Both the resin and the FPLC System were purchased from Pharmacia Biotechnology, Sweden. The phosphates were eluted through a potassium chloride gradient $0-1 \mathrm{M}$ in a triethanolamine buffer, $20 \mathrm{mM}, \mathrm{pH}$ 8.0.

Regression lines were calculated to compare the results obtained from different phenotypes and by different methods (spectrophotometric and gasometric) and under different conditions (in both presence and absence of $\mathrm{Cl}^{-}$ 
ions). In these regression equations $(y=a x+b) a$ can be considered the Bohr effect.

\section{Results}

Electrophoreses showed one slow band for $\mathrm{Hb} \mathrm{A}$, a fast one for $\mathrm{Hb} \mathrm{B}$ and two bands for the heterozygous $\mathrm{Hb}$ AB.

Figures 1, 2 and 3 show the results obtained with oxygen equilibrium experiments on the three phenotypes $-\mathrm{Hb}$ $\mathrm{A}, \mathrm{Hb} \mathrm{AB}$ and $\mathrm{Hb} \mathrm{B}$, using blood and stripped hemoglobin in the presence of the chloride ion, respectively.

The cooperativity showed by stripped $\mathrm{Hb} \mathrm{A}$, in the presence of the chloride ion, was different from those of $\mathrm{Hb}$ $\mathrm{B}$ and $\mathrm{Hb} \mathrm{AB}$. The Student $t$ tests showed that $n$ values were independent of $\mathrm{pH}$, in the three hemoglobin phenotypes: regression lines drawn were parallel to the abscissa axis. Therefore, the differences in $n$ values for $\mathrm{Hb} \mathrm{A}$, represented by $b$ in the regression lines, varied significantly from those of $\mathrm{Hb} \mathrm{B}$ and $\mathrm{Hb} \mathrm{AB}$, at the 0.05 level. No significant difference between $n$ values of $\mathrm{Hb} \mathrm{B}$ and $\mathrm{Hb} \mathrm{AB}$ was detcted. $\mathrm{Hb}$ A presented $n$ values below 2 while $\mathrm{Hb} \mathrm{B}$ and $\mathrm{Hb} \mathrm{AB}$ presented values greater than 2 (Figure 3 ).

Figure 5 shows the results obtained in oxygen equilibrium experiments on the three phenotypes - $\mathrm{Hb} \mathrm{A}, \mathrm{Hb} \mathrm{B}$ and $\mathrm{Hb} \mathrm{AB}$, using stripped hemoglobin in the absence of the the chloride ion.

No differences were observed in oxygen affinity and Bohr effect among $\mathrm{Hb} \mathrm{A}, \mathrm{Hb} \mathrm{B}$ and $\mathrm{Hb} \mathrm{AB}$ in experiments with stripped hemoglobin in the absence of the chloride ion. However, these results are different from those using blood and stripped hemoglobin in the presence of the chloride ion.

Table I shows Bohr effect values obtained under various conditions.

Plotting log P50 against 2,3-diphosphoglycerate (2,3-DPG) concentrations confirmed its weak effect on cattle hemoglobin. (7). However 2,3-DPG seemed to be more

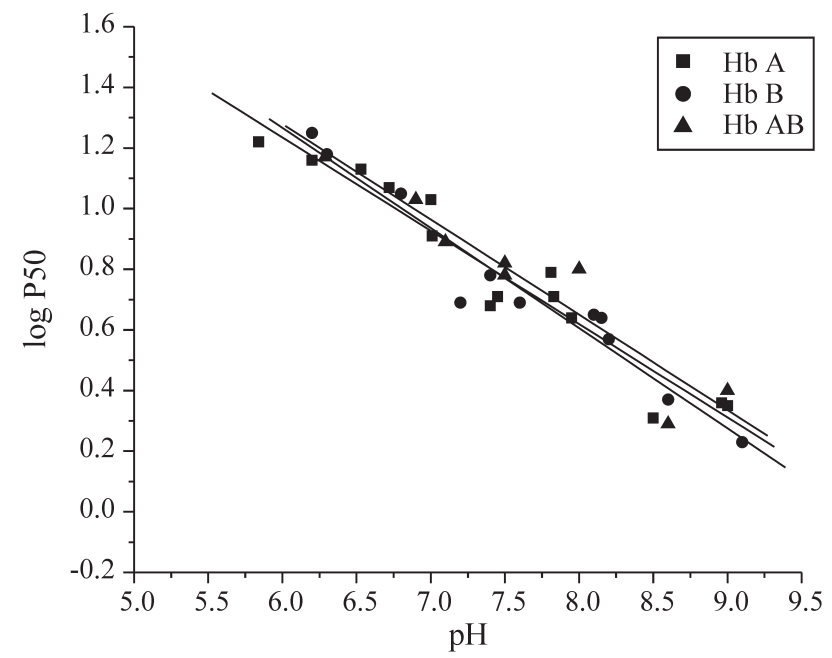

Figure 1 - pH dependence of P50 in blood. Buffer Tris-HCl $0.1 \mathrm{M}$. Showing regression lines in each phenotype.
Table I - Bohr effect values $(\phi)$ of the three phenotypes in different experimental conditions.

\begin{tabular}{lccc}
\hline & A & AB & B \\
\hline Blood & -0.35 & -0.30 & -0.31 \\
Stripped in presence of $\mathrm{Cl}^{-}$ & -0.36 & -0.32 & -0.35 \\
Stripped in absence of $\mathrm{Cl}^{-}$ & -0.18 & -0.12 & -0.19 \\
\hline
\end{tabular}

effective on $\mathrm{Hb} \mathrm{B}$ than on $\mathrm{Hb} \mathrm{A}$ and $\mathrm{Hb} \mathrm{AB}$, in molar ratios $\mathrm{Hb}: \mathrm{DPG}$ of 1:20 (5 $\mu \mathrm{M} \mathrm{Hb}: 100 \mu \mathrm{M}$ of 2,3-DPG) or higher (Figure 4).

The concentration of 2,3-DPG in erythrocytes was $1.27 \mu \mathrm{M} / \mathrm{mL}$ packed red cells for $\mathrm{Hb} \mathrm{A}, 1.3 \mu \mathrm{M} / \mathrm{mL}$ for $\mathrm{Hb}$ $\mathrm{B}$ and $1.01 \mu \mathrm{M} / \mathrm{mL}$ for $\mathrm{Hb} \mathrm{AB}$.

$\mathrm{O}_{2}$ affinity experiments using $\mathrm{Hb} A$ and $\mathrm{Hb} B$ stripped of the chloride ion showed different sodium chloride titration curves (Figure 6).

\section{Discussion}

The absence of difference in oxygen affinity among $\mathrm{Hb} \mathrm{A}, \mathrm{B}$ and $\mathrm{AB}$ phenotypes was expected. This had been shown in previous results from experiments with Canchim cattle (17) comparing $\mathrm{O}_{2}$ affinities of $\mathrm{Hb} \mathrm{A}$ and $\mathrm{Hb} \mathrm{B}$ at 5

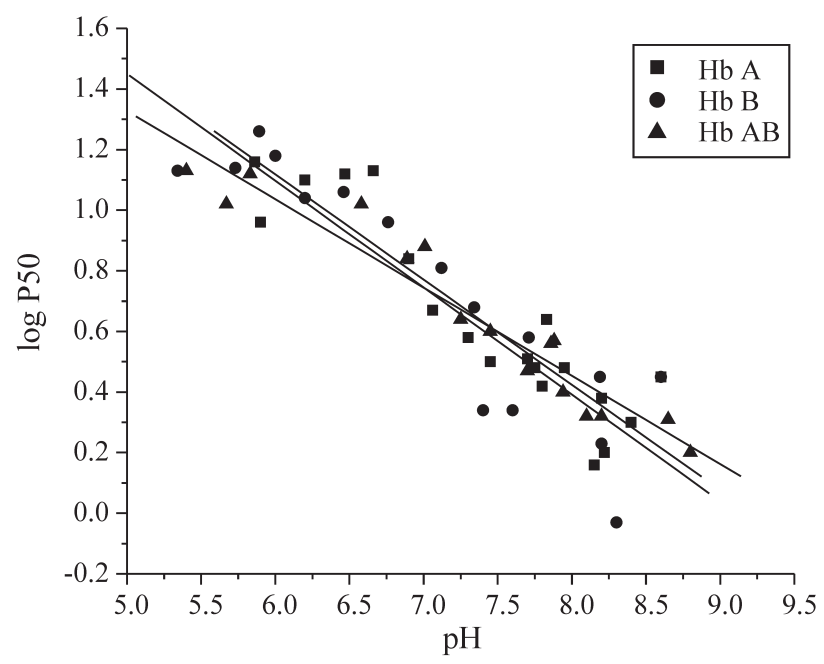

Figure 2 - $\mathrm{pH}$ dependence of P50 in stripped hemoglobin in presence of the chloride ion. Buffer Tris- $\mathrm{HCl} 0.05 \mathrm{M}$. Showing regresion lines in each

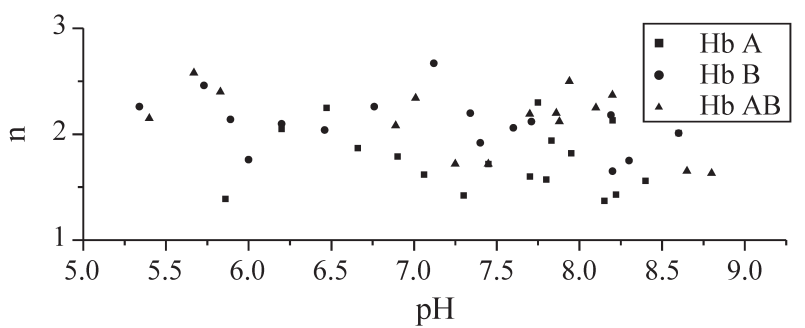

Figure 3 - $\mathrm{pH}$ dependence of $n$ values in stripped hemoglobin in the presence of the chloride ion. Buffer Tris-HCl 0.05 M. 
different $\mathrm{pHs}$. However, the P50 obtained for the latter was around $3.2 \mathrm{mmHg}$ at $\mathrm{pH} 7.4$ for the 3 phenotypes, while that presented in this paper was 4.3. In our laboratory a blood and hemolysate sample of dairy cattle (Holstein Friesan) showed a $\mathrm{P} 50=6.3$ at the same $\mathrm{pH}$. In hemoglobin samples of adult Belgian White Blue cattle a $\mathrm{P} 50=25 \mathrm{mmHg}$, at $\mathrm{pH}$ 7.4 , was found (18). These differences may be due to different $\mathrm{Cl}^{-}$concentrations.

A less likely hypothesis would be the following: cattle hemoglobin separated by liquid chromatography on rigid resin Mono Q, besides the main peak or peaks ( $\mathrm{Hb} \mathrm{A}$, $\mathrm{Hb} \mathrm{B}$ or both) showed two to three small peaks (Vito, Schwantes and Schwantes, in preparation). On the other hand most of the Artiodactylae, especially bovine, showed one to six minor hemoglobin components in isoelectric focusing on polyacrylamide gels (19). Although Bos taurus is not included in the latter paper, its hemoglobin heterogeneity might be expected. The differences in the P50 values mentioned above could be due to variations in relative concentrations of these minor peaks. Differences in amino acid sequences, not detected by the usual electrophoretic methods, could also explain variations found in the stripped hemoglobin P50 in diverse cattle populations.

The $n$ values here obtained with stripped hemoglobin in the presence of the chloride ion indicate cooperativity in $\mathrm{Hb} \mathrm{B}$ and $\mathrm{Hb} \mathrm{AB}$, but very low, if any, in $\mathrm{Hb} \mathrm{A}$. These results are shown in experiments with stripped hemoglobin in the presence of the chloride ion. Since in tropical countries, due to high environmental temperatures, and consequently greater energy requirements than those in temperate areas, the cooperativity of $\mathrm{Hb} \mathrm{B}$ carriers could facilitate oxygen uptake and release. Thus, an advantage over $\mathrm{Hb} \mathrm{A}$ homozygotes could be supposed. However, it is unlikely that cooperativity of $\mathrm{Hb} \mathrm{B}$ and $\mathrm{AB}$ is the only factor and further studies, especially on comparative respiration physiology of individuals showing different $\mathrm{Hb}$ phenotypes, should be performed to find out the real contribution of the $\mathrm{Hb} \beta^{\mathrm{B}}$ gene to the apparent adaptation of their carriers in the tropics. On the other hand, no differences in $n$ values were obtained in these experiments with stripped hemoglobin in the absence of the chloride ion. No differences in cooperativity among the three phenotypes were found in the $\mathrm{Cl}^{-}$titration experiments. However, the dimerization effect of $\mathrm{NaCl}$ (used as the $\mathrm{Cl}^{-}$source) on cooperativity cannot be ruled out. The P50 values decreased above $1.2 \mathrm{mM} \mathrm{NaCl}$. These data suggest that the reverse of the slopes obtained at high ionic strength would be consistent with salt dissociation induction of tetramers into dimers (20).

No differences among oxygen affinity and the Bohr effect of $\mathrm{Hb} \mathrm{A}, \mathrm{Hb} \mathrm{AB}$ and $\mathrm{Hb} \mathrm{B}$ were obtained here when compared in blood or stripped hemoglobin, in the presence or absence of the $\mathrm{Cl}^{-}$ion. The lack of differences between blood and stripped hemoglobin in the presence of $\mathrm{Cl}^{-}$as well as the higher $\mathrm{O}_{2}$ affinity of samples in the absence of this ion were confirmed. Apparently, the sensitivity to chloride ion is greater for $\mathrm{Hb} \mathrm{A}$ than for $\mathrm{Hb} \mathrm{B}$ in $\mathrm{NaCl}$ concen-

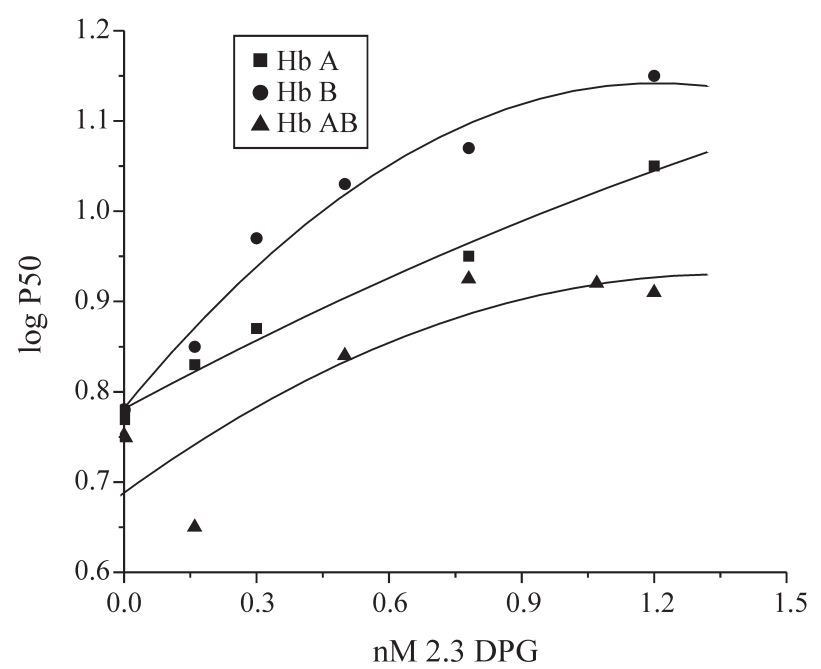

Figure 4 - Influence of the concentration of 2,3DPG on the P50, $\mathrm{pH} 6,9$.

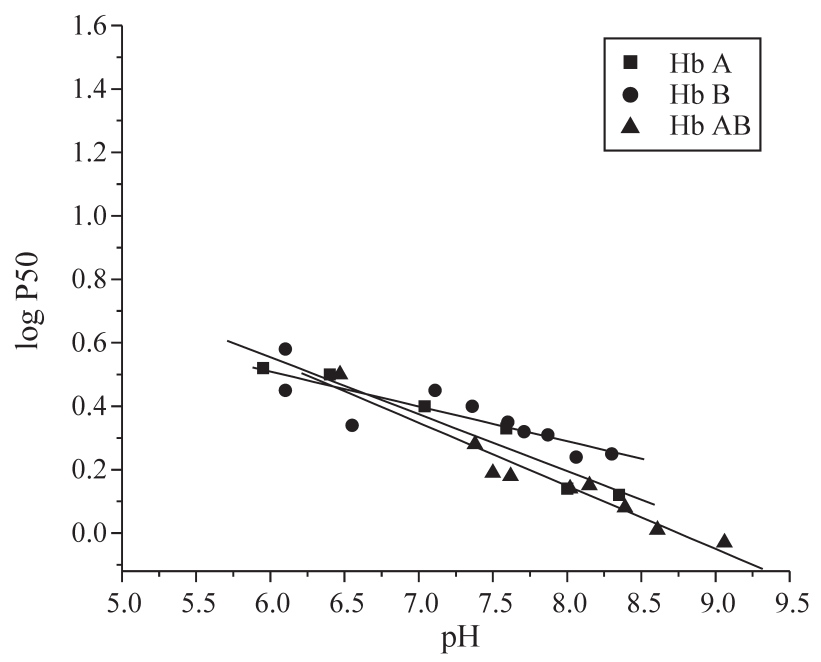

Figure 5 - $\mathrm{pH}$ dependence of P50 in stripped hemoglobin in the absence of the chloride ion. Buffer Hepes-Tris 0.1 M. Showing regression lines in each phenotype.

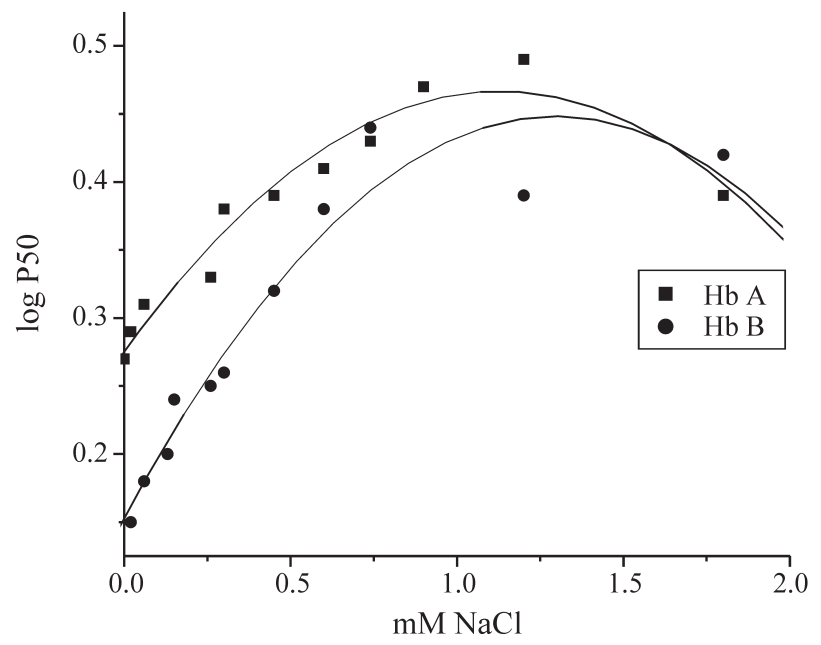

Figure 6 - Influence of the concentration of $\mathrm{NaCl}$ on the P50. Buffer Hepes-Tris $0.1 \mathrm{M}, \mathrm{pH} 7.4$. 
trations less than $0.75 \mathrm{mM}$. However, when concentration of this salt in the experimental solution was higher than $0.75 \mathrm{mM}$, this difference disappeared.

The apparent effectiveness of high 2,3-DPG: Hb molar ratios does not seem to be important for bovine $\mathrm{Hb}$ adaptation, since the concentration of this organic phosphate never reaches the necessary concentration to play any role in its respiration. It is interesting to point out, that in terms of cooperativy the $\mathrm{Hb} \beta^{\mathrm{B}}$ is dominant over the $\mathrm{Hb} \beta^{\mathrm{A}}$ gene, while in terms of DPG biding, $\mathrm{Hb} \beta^{\mathrm{A}}$ is the dominant gene.

\section{Acknowledgments}

This work could not have been done without the help of several researchers and technicians form EMBRAPAUEPAE São Carlos (Fazenda Canchim) who provided the samples for this study. Alfredo Di Vito Neto has held fellowships from FAPESP, CAPES and CNPq during different phases of the present work. This work was supported by CNPq, FAPESP and CAPES. The authors, wish to thank Dr. Paula Ann Matvienko-Sikar, who critically reviewed this manuscript.

\section{References}

Ayala FJ (1982) Population and Evolutionary Genetics, The Benjamin Cummings Publishing Company, Inc. Menlo Park, California.
Bartlett GR (1959) J. Biol. Chem. 234:466.

Bunn HF (1971) Science 172:1049.

Butcher PD and Hawkey CM (1971) Comp. Biochem. Physiol. 56B:335.

Cabannes R and Serain CH (1995) Comptes Rendus Soc. Biol. 149:5.

Fronticelli CA (1990) Biophysical Chemistry 37:141.

Giri KV, Pillai NC (1965) Nature 178:1057.

Gustin P, Clerbaux Th, Willems E, Lekeux P, Lomba F and Frans (1988) Comp. Biochem. Physiol. 89:553.

Johansen L, Mangun CP, and Lykkeboe G (1978) Can. J. Zool. 56:898.

Kellett GL (1977) J. Mol. Biol. 59:401.

Lehmann H, Rossi JG. Man, 61:81, 1961.

Masina P, Iannelli D, Iorio M, Ramunno L (1977) Anim. Blood Grps Biochem. Genet. 8:65.

Perutz MF and Fermi G (1993) J. Mol. Biol. 233:536.

Petersen CG, Schwantes R, and Schwantes MLB (1989) Comp. Biochem. Physiol. 94B:823.

Riggs, and Wolbach R (1955) J. Gen. Physiol. 39:585.

Schroeder WA, Shelton JR, Robberson B and Babin DR (1967) Archs Biochem. Biophys. 120:124.

Schwantes R, Schwantes MLB, Bonaventura C, Sullivan B and Bonaventura J (1976) Comp. Biochem. Physiol. 54B:447.

Teixeira U Estudos do polimorfismo de hemoglobina em gado Canchim, Master Dissertation, São Carlos, 1980.

Val L, Schwantes R, Schwantes MLB and De Luca PH (1981) Ciência e Cultura 33:982.

Weber RE, Lalthantluanga R and Braunitzer G (1988) Archs. Biochem. Biophys. 263:199. 